„Umwelteinflüsse auf Allergie und Asthma im Kindesalter" statt. Zudem wird es wieder eine Junior-Members-ePosterSession geben, in der Fallbeispiele aus der Klinik und auch Daten aus der Grundlagenforschung vorgestellt werden können. Wenn bei der Einreichung des Abstracts angegeben wird, dass der Beitrag auch in der Junior-MembersSession präsentiert werden soll, kann man als Junior Member mit aktiver Beteiligung auch dieses Jahr kostenlos am Kongress und zusätzlich am Gesellschaftsabend teilnehmen.

Wir heißen weiterhin jeden Willkommen, der aktiv an der Gestaltung unserer Sektion sowie der Planung der JuniorMembers-Symposien teilnehmen möchte und freuen uns auf weitere erfolgreiche Jahre! Mehr Informationen zu den Junior Members der DGAKI und deren Veranstaltungen gibt es nun auch auf der Facebook-Seite der Junior Members: www. facebook.com/DGAKIJuniorMembers.

Maximilian Schiener Dennis Rußkamp

\section{Mainzer Abstract-Preis}

A uch dieses Jahr wurde wieder der A Mainzer Abstract-Preis der DGAKI an die Autoren der drei besten Abstracts vergeben, die eingereicht worden sind. Ausgezeichnet werden herausragende wissenschaftliche Arbeiten, die sich mit diagnostischen und therapeutischen Fragestellungen sowie der Grundlagenforschung auf den Gebieten der Allergologie, der klinischen Immunologie und verwandter Gebiete befassen. Gestiftet wurde der Preis vom Unternehmen ALK-Abelló.

-1. Preis (dotiert mit $1.000 €$ ): PD Dr. Frank Siebenhaar, Hautklinik, Charité - Universitätsmedizin Berlin; Abstract V33: Siebenhaar F, Zimmermann C, Metz M, Maurer M. Mast cell-derived IL- 6 is critical for the healing of infected wounds in mice. Allergo J Int 2016; 25:31

—2. Preis (dotiert mit $750 €$ ): Dr. Joanna Wegner, Hautklinik, Universitätsmedizin Mainz: Abstract V36: Wegner J, Saloga J, Grabbe S, Lutz J, WeinmannMenke J, Stebut von E. Selective IgE immunoadsorption for treatment of

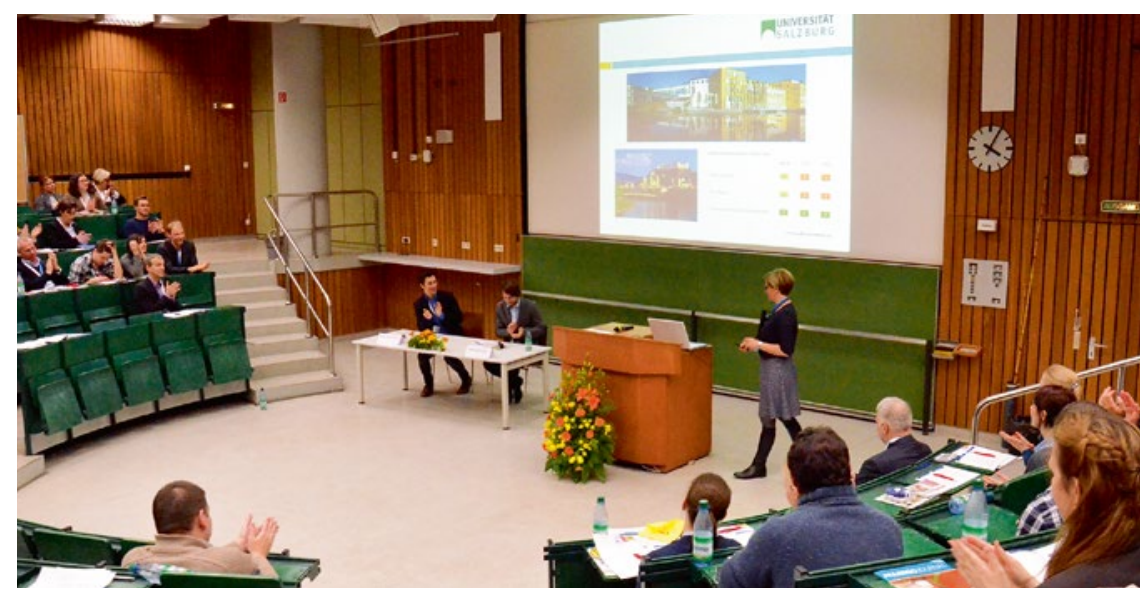

Vortrag von Dr. Gabriele Gadermaier zum Thema "Pollen und deren Kreuzallergene" während des Junior-Members-Symposiums.

Die beiden Sprecher der Junior Members:

Maximilian Schiener (links) und Dennis Rußkamp

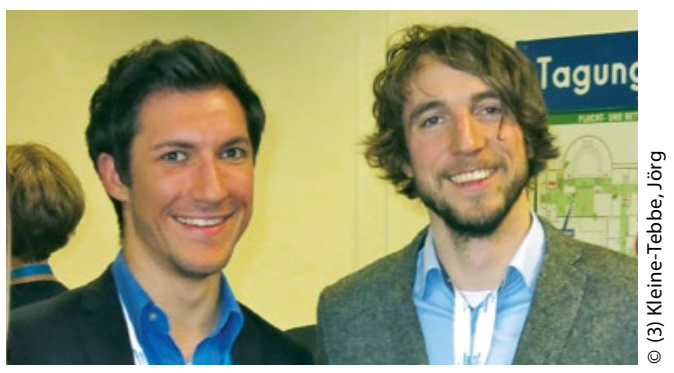

severe atopic dermatitis. Allergo J Int 2016;25:32

-3. Preis (dotiert mit $500 €$ ): Dr. Christiane Hilger, Luxembourg Institute of Health, Luxemburg; Abstract V11: Hilger C, Fischer J, Swiontek K, Hentges F, Lehners C, Eberlein B, Morisset
M, Biedermann T, Ollert M. Identification of two cell-membrane peptidases from pork kidney as galactose- $\alpha$ 1,3-galactose carrying allergens implicated in delayed meat allergy. Allergo J Int 2016;25:22

red

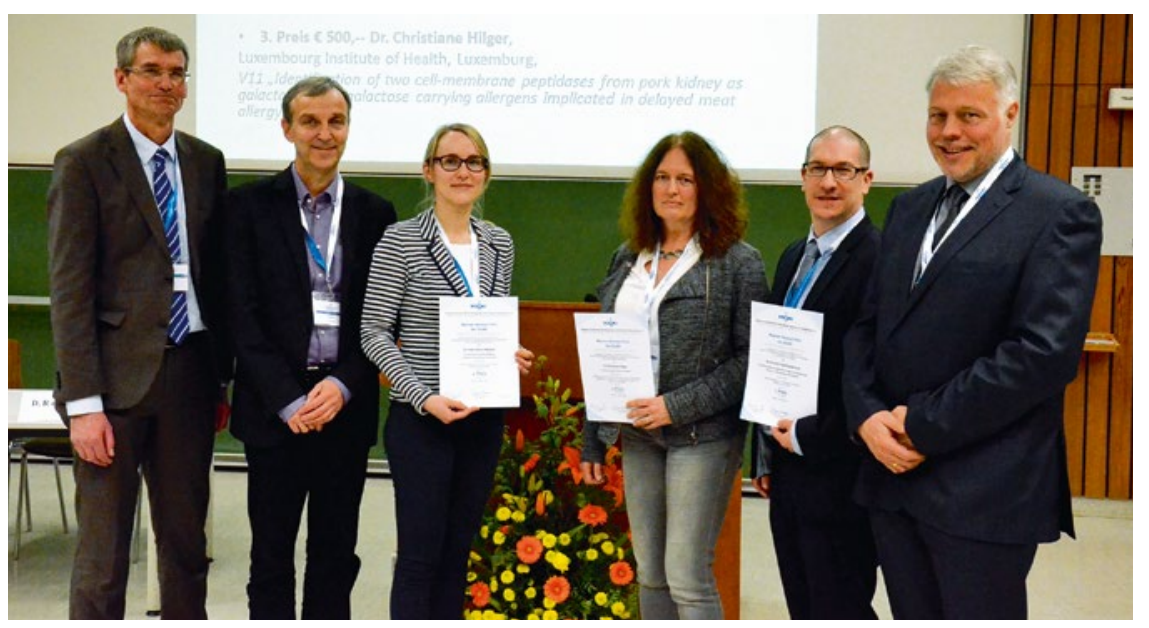

Verleihung des Mainzer Abstract-Preises (von links nach rechts) Dr. Wolf, ALK-Abelló; Prof. Dr. Thomas Werfel, Vizepräsident der DGAKI; Dr. J. Wegner, 2. Preis; Dr. C. Hilger, 3. Preis, PD Dr. F. Siebenhaar, 1. Preis und Prof. Dr. Joachim Saloga, Tagungsleiter 